\title{
reviews
}

\section{Nature/nurture between the Wars}

William J. Schull

The Triumph of Evolution: American Scientists and the Heredity/Environment Controversy, 1900-1941. By Hamilton Cravens. (University of Pennsylvania Press: Philadelphia, 1978.) $\$ 17.50$.

Hamilton Cravens' The Triumph of Evolution describes the sequence of events in the United States between the two World Wars which he contends led to the resolution of the heredityenvironment controversy. Whether, indeed, a resolution has occurred, as he asserts, may seem dubious to one who follows Nature's book pages and the controversy over the roles of nature and nurture in differences in intelligence, or whatever it is that intelligence tests measure. Resolution here, however, merely means the achievement of an agreement among natural and social scientists that nature and nurture are distinct but interdependent variables.

The central theme of this book is that the sudden increase in the last decade of the nineteenth century of experimental biology and psychology, aided by the emergence of the new graduate universities, fostered an academic professionalisation of these sciences which had and continues to have profound repercussions. It led to changes in educational emphases in these institutions and encouraged the development of the accoutrements of science which we now take for granted. Numerous professional societies and journals were born, and a scurry for research resources begun which persists unabated. Out of this process, Cravens maintains, came consensus. A little lamented casualty was social Darwinism, at least in its most strident forms, whose adherents waned as the new professionals grew in number.

A complicated, somewhat conjectural but nonetheless intriguing series of events and developments in anthropology, genetics, psychology and sociology is set forth to support this central thesis. Much of Cravens' argument emerges through an analysis of the actions and inactions of the prominent figures of the time in the aforementioned disciplines. Some of these individuals intrigue him more than others. Franz Boas is such a case, but Davenport, Morgan, Ross, Yerkes,
Dewey, Watson, Thorndike and Cattell - to mention but a few others-have their moments of attention. The activities of these individuals and their students are often interpreted in terms of their ethnic, religious and social affiliations. Their contributions to their branches of science as well as their academic and social fates are briefly limned. Most are treated sympathetically with possibly Charles Davenport emerging as the most prejudiced, least principled and least qualified of the major personalities. Familiar lesser figures such as Madison Grant, Harry Laughlin and Henry Goddard receive short shrift as is their due. To these three are ascribed some of the more sordid chapters in the eugenics movement in the United States and rightly so.

Cravens' is not the first analysis of many of these events. Kenneth Ludmerers' Genetics and American Society: A Historical Appraisal (1972) and Mark Haller's Eugenics: Hereditarian Attitudes in America Thought (1963), for examples, trace many of the same developments, and often somewhat more thoroughly but from quite a different perspective. This book makes more of the events which were occurring in the new universities, their strivings for distinction among their peers, and the emergence of a scientific community in the New World not wholly dependent upon that in the Old for its directions and philosophy. It prompts thought on the unusual impact that a few forceful personalities may have upon a discipline; witness Boas' imprint on anthropology.

Cravens' analysis does not strike me as especially disputatious. It is thoughtful and built on a serious consideration of a variety of materials - biographies, letters, journals, society proceedings and the like. Few will be able to read The Triumph of Evolution and not be exposed to new facts or facets in this controversy. The geneticist will learn of the turmoil his science provoked in the social sciences, and should be able to appreciate positions which may have merely seemed obdurate in the past. Similarly the cultural anthropologist, say, should learn more of the history of twentieth-century genetics, and the origins of its collective perspective. All will be exposed to parallelisms of which most readers will have been previously unaware. Many will be tempted to read further, and the extensive notes with which the book concludes will prove invaluable.

This otherwise interesting and generally unexceptionable book is marred in my view by two shortcomings. First, it is unnecessarily repetitive. Much of the contents of the chapter "The New Biology" is repeated elsewhere. We are told, for example, on p24 of G. Stanley Hall's strengths and weaknesses as the President of Clark University and much the same material appears again on p65. Edward East receives similar double treatment on $\mathrm{pp} 51$ and 169. Others fare in like manner. There is moreover a tiresome repetition of labels which brings me to my second objection. The Triumph of Evolution is flawed by the frequent use of stereotypes of people and institutions. We read of the white, Anglo-Saxon, Protestant; the left-liberal; the gentle Quaker and the humble normal school. While these may be handy labels and often serve a useful, albeit pejorative purpose in political tracts, they seem out of place to me in an historical account of this nature. H. J. Muller, for example, is variously characterised as brilliant, a radical, a man with leftliberal tendencies. Most who knew him would accept all of these appellations as valid. But he could equally well have been described as an elitist, an uncommonly gifted investigator with an incredible biological intuition, or a teacher who could communicate the excitement he found in genetics to students and colleagues alike. But do any of these labels provide a compelling basis for characterising him as one who was "quite willing to tolerate the eugenics movement and to perhaps even support some of its goals so long as the movement appeared disinterested, scientifically credible, and dignified"? I'm not questioning the attribution but merely its justification on no more forceful evidence, seemingly than a series of labels. These are poor substitutes for a penetrating analysis of the man.

William J. Schull is Director of the Center for Demographic and Population Genetics, University of Texas Health Science Center, Houston, Texas. 